\title{
Chronic Exposure to Particulate Hexavalent Chromium Alters Cdc20 Protein Localization, Interactions and Expression
}

\section{Naga D. Karri, Hong Xie and John Pierce Wise Sr.*}

Wise Laboratory of Environmental and Genetic Toxicology, Maine Center for Toxicology and Environmental Health, Department of Applied Medical Science, University of Southern Maine, USA

\begin{abstract}
Hexavalent chromium $[\mathrm{Cr}(\mathrm{VI})]$ compounds are well established human lung carcinogens, but it is unknown how they cause lung cancer in humans. Recent data indicate that $\mathrm{Cr}(\mathrm{VI})$ induces chromosome instability in human lung cells, and genomic instability is considered a leading mechanism to explain chromate carcinogenesis. The spindle assembly checkpoint (SAC) is a critical regulator of the metaphase-to-anaphase transition and ensures genome stability by preventing chromosomal missegregation events. Bypass of the SAC can lead to genomic instability, manifested as aneuploidy, which eventually leads to tumor formation and cancer. Recent studies in our laboratory demonstrated that chronic exposure to zinc chromate induces SAC bypass in a concentration- and time-dependent manner in human lung fibroblasts. To further study these events, we focused on the cell division cycle 20 (Cdc20) protein, a downstream effector protein in the SAC. Cdc20 has not been studied after $\mathrm{Cr}(\mathrm{VI})$ exposure, but other studies show that experimentally-induced alterations of Cdc20 localization to kinetochores or of Cdc20 protein expression leads to aneuploidy. Here, we investigated the effects of zinc chromate, a particulate $\mathrm{Cr}(\mathrm{VI})$ compound, on $\mathrm{Cdc} 20$ localization, protein expression and interactions. Our data show $\mathrm{Cdc} 20$ is a target for particulate $\mathrm{Cr}(\mathrm{VI})$. Chronic zinc chromate exposure altered Cdc20 kinetochore localization and reduced the interaction of phosphorylated Cdc20 with Mad2, which may underlie zinc chromate-induced SAC bypass.
\end{abstract}

Keywords: Hexavalent chromium; Zinc chromate; Cdc20; Mad2; Spindle assembly checkpoint; Spindle assembly checkpoint bypass

Abbreviations: $\mathrm{Cr}(\mathrm{VI})$ : Hexavalent Chromium; SAC: Spindle Assembly Checkpoint; CIN: Chromosome Instability

\section{Introduction}

Hexavalent chromium $[\mathrm{Cr}(\mathrm{VI})]$ is a known human lung carcinogen and the solubility of $\mathrm{Cr}(\mathrm{VI})$ plays an important role in its carcinogenicity [1-3]. Epidemiologic studies show a higher lung cancer risk for particulate- $\mathrm{Cr}(\mathrm{VI})$-exposed workers [2], and experimental studies show that only particulate $\mathrm{Cr}(\mathrm{VI})$ compounds induce tumors in animal models and neoplastic transformation of cultured mouse embryo cells $[2,4]$. However, despite its potent carcinogenicity, the carcinogenic mechanism for $\mathrm{Cr}(\mathrm{VI})$ is poorly understood.

Chromosome Instability (CIN) consisting of alterations of both chromosome number and structure is a hallmark of human lung cancer [5]. Cell culture studies show that both particulate and soluble $\mathrm{Cr}(\mathrm{VI})$ compounds can induce CIN in human lung cells and that human bronchial epithelial cells malignantly transformed by $\mathrm{Cr}(\mathrm{VI})$ exhibit an aneuploid phenotype [6,7]. Further data show that mechanisms underlying $\mathrm{Cr}(\mathrm{VI})$-induced numerical $\mathrm{CIN}$ involve centrosome amplification and bypass of the spindle assembly checkpoint (SAC) $[7,8]$.

The SAC acts as a quality control mechanism for accurate chromosome segregation during mitosis [9]. It delays anaphase until all chromosomes are correctly attached to the mitotic spindle. Bypassing the SAC can lead to chromosome missegregation and aneuploidy. We previously showed that chronic exposure to particulate $\mathrm{Cr}(\mathrm{VI})$ compounds leads to SAC bypass manifested as centromere spreading, premature centromere division, and premature anaphase $[7,8]$. These metaphase disruptions occurred despite the presence of an intact, functioning SAC indicating that particulate $\mathrm{Cr}(\mathrm{VI})$ is able to bypass the induction of the SAC and allow metaphase cells premature entry into anaphase. However, the mechanism that underlies how $\mathrm{Cr}(\mathrm{VI})$ exposure disrupts the SAC is unknown.

The primary effector in the SAC is Cdc20, which is an essential activator of the anaphase promoting complex/cyclosome (APC/C). As a mitotic cell becomes organized in metaphase, Cdc20 is recruited and localized to the kinetochore and combined with the Mad2, BubR1and Bub3, proteins into a mitotic checkpoint complex (MCC). This complex then prevents Cdc20 from activating APC/C, preventing the start of anaphase [10]. When a metaphase cell is ready to progress into anaphase, the MCC releases Cdc20 so it can bind and activate APC/C. Once activated, APC/ Cubiquinates securin causing securin to release separase, which then cleaves cohesin separating the chromatid arms and anaphase ensues.

Data show that disrupting Cdc20 can lead to aneuploidy and cancer. For example, alteration of Cdc20 expression is associated with impairment of the SAC and aneuploidy in cancer [11]. Mutations or/ and dysregulated expression of $\mathrm{Cdc} 20$, has been found in breast cancer cells [12]. Loss of Mad2-Cdc20 interactions due to mutant Cdc20 promotes tumor formation in mice [13]. Myeloma cells are highly aneuploid and have very low levels of $\mathrm{Cdc} 20$ and $\mathrm{Mad} 2$ protein [14] Female mice that express low levels of Cdc20 produce aneuploid oocytes

${ }^{*}$ Corresponding author: Dr. John Pierce Wise, Sr., Maine Center for Toxicology and Environmental Health, Department of Applied Medical Science, University of Southern Maine, 96 Falmouth St., Portland, ME. 04104-9300, USA, Tel: (207) 2288050; Fax: (207) 228-8057; E-mail: John.Wise@usm.maine.edu

Received January 15, 2013; Accepted March 20, 2013; Published March 28 2013

Citation: Karri ND, Xie H, Wise JP (2013) Chronic Exposure to Particulate Hexavalent Chromium Alters Cdc20 Protein Localization, Interactions and Expression. J Carcinogene Mutagene 4: 140. doi:10.4172/2157-2518.1000140

Copyright: ( 2013 Karri ND, et al. This is an open-access article distributed under the terms of the Creative Commons Attribution License, which permits unrestricted use, distribution, and reproduction in any medium, provided the original author and source are credited. 
and embryos [15]. Cadmium, a human carcinogen, reduces Cdc20 protein levels leading to disruption of early mitotic progression [16]. However, the impact of $\mathrm{Cr}(\mathrm{VI})$ on $\mathrm{Cdc} 20$ has not been studied. Thus, this study determined the impact of $\mathrm{Cr}(\mathrm{VI})$ on $\mathrm{Cdc} 20$ considering its effects on Cdc20 kinetochore localization, its interactions with Mad2 and its protein expression levels.

\section{Material and Methods}

\section{Chemicals and reagents}

Zinc chromate was purchased from Alfa Aesar (Ward Hill, MA). Demecolchicine and nocodazole were purchased from Sigma/Aldrich (St. Louis, MO). Dulbecco's modified eagle's medium/Ham's F-12 (DMEM/F-12) 50:50 mixture and phosphate-buffered saline (PBS) were purchased from Mediatech Inc. (Herndon, VA). Cosmic calf serum (CCS) was purchased from Hyclone (Logan, UT). GlutaMAX, sodium pyruvate, trypsin/EDTA and penicillin/streptomycin were purchased from Invitrogen Corporation (Carlsbad, CA). Tissue culture flasks, dishes and plasticware were purchased from BD (Franklin Lakes, NJ).

\section{Cells and cell culture}

Human lung fibroblasts were used as the cell model system for this study, specifically, WTHBF-6 cells, a clonal cell line derived from normal human bronchial fibroblasts. These cells exhibit a stable, normal diploid chromosome complement and similar clastogenic and cytotoxic responses to metals compared to their parent cells [17]. These cells ectopically express human telomerase and thus, have an extended lifespan. Cells were cultured as subconfluent monolayers in DMEM/F-12 media supplemented with $15 \%$ CCS, $100 \mathrm{U} / \mathrm{ml}$ penicillin/100 ug/ml streptomycin, $2 \mathrm{mM}$ glutaMAX and $0.1 \mathrm{mM}$ sodium pyruvate. They were incubated at $37^{\circ} \mathrm{C}$ and in $5 \%$ carbon dioxide. They were fed every two days and subcultured at least once a week using $0.25 \%$ trypsin/1mM EDTA solution. Experiments were performed on logarithmically growing cells.

\section{Metal preparation}

Zinc chromate was used as a representative particulate $\mathrm{Cr}(\mathrm{VI})$ compound and administered as a suspension in cold water, as previously described [18]. Cells were treated with $0,0.1,0.15$ and 0.2 $\mathrm{ug} / \mathrm{cm}^{2}$ zinc chromate for 24, 48, 72, 96 and $120 \mathrm{~h}$.

\section{Antibodies}

Rabbit anti-human Cdc20, mouse anti-human Mad2, rabbit anti-phosphoserine and mouse anti-glyceraldehyde 3-phosphate dehydrogenase (GAPDH) antibodies were purchased from Abcam (Cambridge, MA). Mouse anti-human Cdc20 antibody was purchased from Millipore (Billerica, MA). Mouse anti- $\beta$-actin antibody was purchased from Rockland (Gilbertsville, PA). Human anti-centromere serum was provided as a gift from Dr. William Earnshaw from the University of Edinburg (Edinburg, Scotland, UK). AlexaFluor 555 goat anti-mouse IgG and AlexaFluor 488 goat anti-human IgG antibodies were purchased from Molecular Probes (Eugene, OR). Goat anti-rabbit $\operatorname{IgG}(\mathrm{H}+\mathrm{L})-\mathrm{HRP}$ and goat anti-mouse IgG $(\mathrm{H}+\mathrm{L})$-HRP secondary antibody conjugate were purchased from Bio-Rad (Hercules, CA).

\section{Western blot analysis}

Western blot analysis was performed according to our published methods [18]. Briefly, after zinc chromate treatment, whole cell population or mitotic cell population by mitotic shake off were lysed with RIPA lysis buffer for 15 minutes on ice. Protein concentrations were analyzed by the Bradford protein assay using a Nanodrop spectrophotometer. Equal protein was resolved using 10\% SDSpolyacrylamide gel electrophoresis (PAGE) and then transferred on to a 0.45 um pure nitrocellulose membrane. The membrane was then blocked with $5 \%$ non-fat milk and probed with anti-Cdc20 or antiMad2 antibody overnight at $4^{\circ} \mathrm{C}$, followed by $1 \mathrm{~h}$ incubation with horseradish peroxidase conjugated anti-rabbit or anti-mouse IgG secondary antibody. The blots were visualized using ECL plus detection reagent and images were taken using the Storm 840. GAPDH was used as a loading control. At least three independent experiments were performed.

\section{Immunofluorescence analysis}

Immunofluorescence analysis was performed according to our published methods [18]. Briefly, cells were seeded onto one-well chamber slides and treated with $0-0.2 \mathrm{ug} / \mathrm{cm}^{2}$ of zinc chromate for 24-120 h. After treatment, cells were fixed with $4 \%$ paraformaldehyde, permeabilized with $0.25 \%$ Triton X-100 and blocked with blocking buffer. Cells were then incubated with anti-Cdc20 and anti-centromere serum for $1 \mathrm{~h}$. Cells were washed and then incubated with anti-mouse Alexa 555 and anti-human Alexa 488 for 1 h. Cells were washed and coverslips were then mounted on slides with Prolong anti-fade with DAPI. The first 50 mitotic cells were analyzed per concentration using fluorescence microscopy. At least three independent experiments were performed.

\section{Immunoprecipitation analysis}

Cell lysates were prepared in RIPA buffer as described above. 500 ug of protein were incubated with anti-Cdc20 antibody-bound beads for two hours using the Crosslink Immunoprecipitation Kit (PierceThermo Fisher Scientific) according to the manufacturer's instructions. Precipitated proteins were released by elution buffer, resolved by SDSPAGE, and specifically detected by immunoblot as described above.

\section{Statistics}

The Student's t-test was used to compute p-values to further determine the statistical significance of the difference in means, with a $\mathrm{p}$ value $<0.05$ or $<0.01$ considered as statistically significant. No adjustment was made for multiple comparisons.

\section{Results}

\section{Chronic exposure to zinc chromate induces decreased Cdc20} localization to the kinetochores

During SAC activation in mitosis, Cdc20 localizes to unattached kinetochores binding with other checkpoint proteins and enzymes to inhibit the metaphase to anaphase transition [19-21]. Studies show that disrupting Cdc20 localization to the kinetochores can attenuate the checkpoint $[13,22]$. Thus, we evaluated the impact of zinc chromate on Cdc20 localization. We found that chronic exposure to zinc chromate induced a time-dependent decrease in Cdc20 localization to the kinetochores (Figure 1) after 48-120 h of exposure, with a pronounced effect starting at $72 \mathrm{~h}$. For example, at $24 \mathrm{~h}$, none of the cells treated with $0.2 \mathrm{ug} / \mathrm{cm}^{2}$ zinc chromate had altered Cdc20 localization. But altered localization was $0.7 \%$ at $48 \mathrm{~h}$ and increased to $22 \%$ at $72 \mathrm{~h}$, $38 \%$ at $96 \mathrm{~h}$ and $47 \%$ at $120 \mathrm{~h}$ (Figure 1B). We also found that chronic exposure to $\mathrm{Cr}(\mathrm{VI})$ induced a concentration-dependent decrease in 
Citation: Karri ND, Xie H, Wise JP (2013) Chronic Exposure to Particulate Hexavalent Chromium Alters Cdc20 Protein Localization, Interactions and Expression. J Carcinogene Mutagene 4: 140. doi:10.4172/2157-2518.1000140

Cdc20 localization to the kinetochores (Figure 1). For example, at $72 \mathrm{~h}$ the amount of altered localization was $0,4,18.7$ and 22 percent of cells after exposure to $0,0.1,0.15$ and $2 \mathrm{ug} / \mathrm{cm}^{2}$ zinc chromate, respectively (Figure 1B).

Chronic exposure to zinc chromate induces decreased Cdc20 and Mad2 protein levels

A growing body of evidence shows that overexpression or underexpression [22-24] of Cdc20 protein leads to premature anaphase promotion, missegregation of chromosomes and aneuploidy, which indicates that maintaining appropriate amounts of Cdc20 is essential in mitosis. Cdc20 protein is constantly being synthesized and degraded with a half life of approximately 30 minutes in human cells [25]. We found that zinc chromate induced a concentration-dependent decrease in protein levels starting after $48 \mathrm{~h}$ of exposure (Figures 2A and 2B). This effect was still evident when we limited our analysis to only those cells in mitosis (Figures 2C and 2D). Using an anti-phosphate antibody, we also found a consistent decrease in phosphorylated Cdc20 levels at

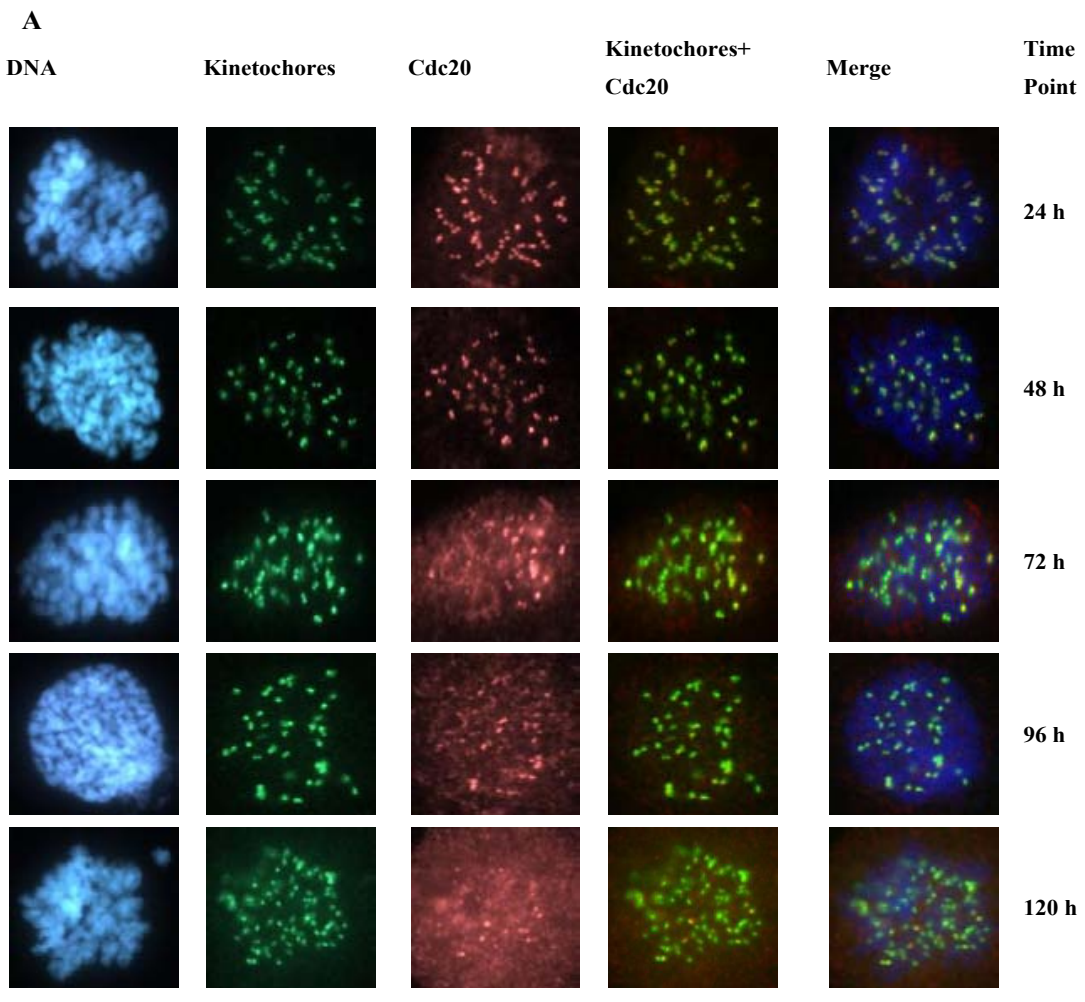

B

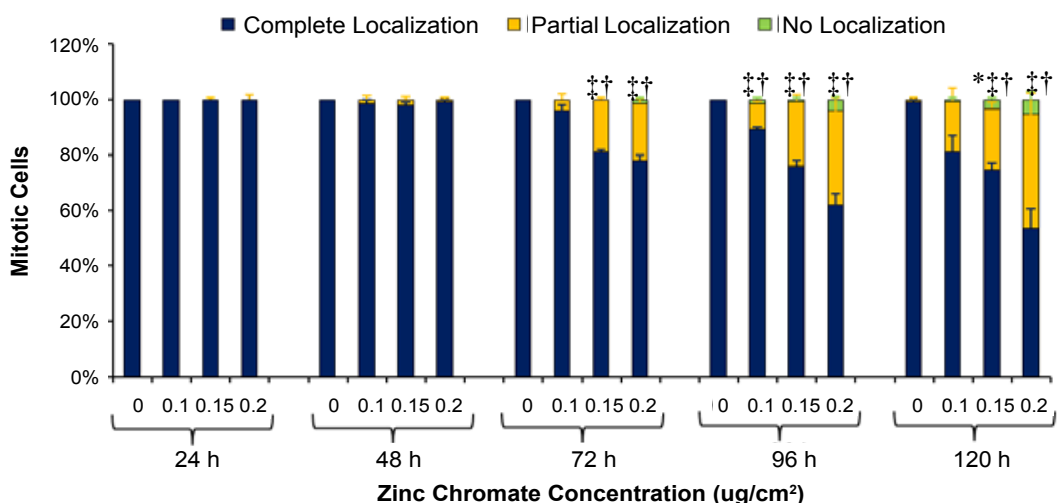

Figure 1: Particulate $\mathrm{Cr}(\mathrm{VI})$ Disrupts Cdc20 Localization to Kinetochores. This figure shows that chronic exposure to zinc chromate induces a concentration- and time-dependent decrease in Cdc20 localization to the kinetochores. A) The representative images of Cdc20 localization to the kinetochores after exposure to 0.2 $\mathrm{ug} / \mathrm{cm}^{2}$ zinc chromate for 24-120 h. Blue (DAPI) represents the DNA, green (Alexa 488) represents the kinetochores (anti-centromere serum) and red (Alexa 555) represents $\mathrm{Cdc} 20$. B) This figure shows that $24 \mathrm{~h}$ exposure to $0-0.2 \mathrm{ug} / \mathrm{cm}^{2}$ zinc chromate induced no changes in Cdc20 kinetochore localization while more chronic exposures $(48-120 \mathrm{~h})$ decreased Cdc20 kinetochore localization. Data represent an average of three independent experiments \pm the standard error of the mean. ${ }^{*} \mathrm{Cells}$ with no Cdc20 localization were statistically different from control $(p<0.05)$, †Cells with partial Cdc20 localization were statistically different from control $(p<0.05)$, $\neq$ Cells with complete Cdc20 localization were statistically different from control $(p<0.05)$. 


\section{A}

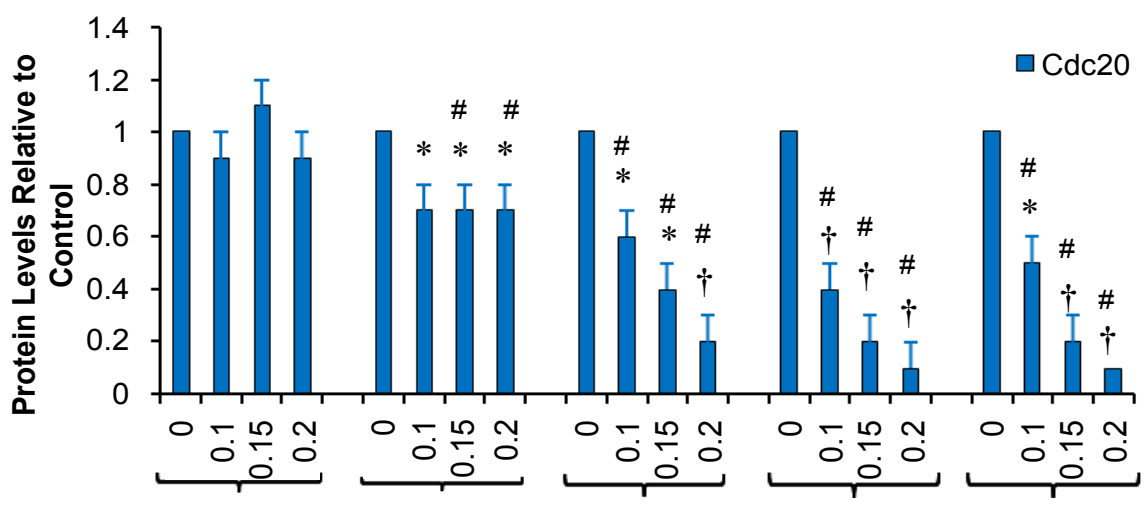

$24 \mathrm{~h}$

$48 \mathrm{~h}$

$72 \mathrm{~h}$

$96 \mathrm{~h}$

$120 \mathrm{~h}$

Zinc Chromate Concentration (ug/ $\mathrm{cm}^{2}$ )

B
Time (h)
24
48
72
96
120

Zinc Chromate

$\begin{array}{lllllllllllllllllllll}\left(\mathrm{ug} / \mathrm{cm}^{2}\right) & 0 & 0.1 & 0.15 & 0.2 & 0 & 0.1 & 0.15 & 0.2 & 0 & 0.1 & 0.15 & 0.2 & 0 & 0.1 & 0.15 & 0.2 & 0 & 0.1 & 0.15 & 0.2\end{array}$

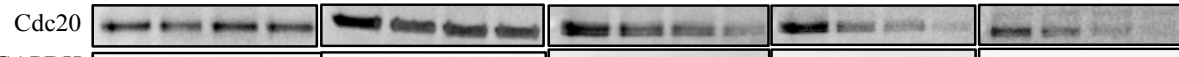

GAPDH

C

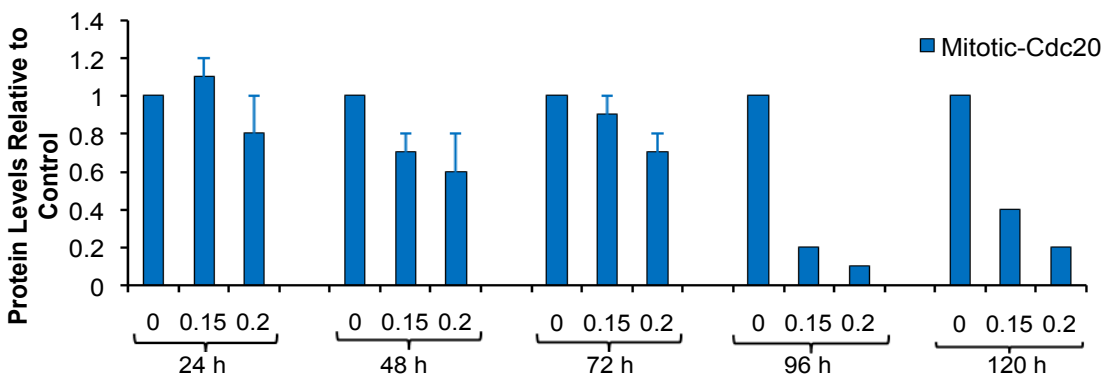

Zinc Chromate Concentration (ug/ $\left.\mathrm{cm}^{2}\right)$

D

$\begin{array}{llllll}\text { Time (h) } & 24 & 48 & 72 & 96 & 120\end{array}$

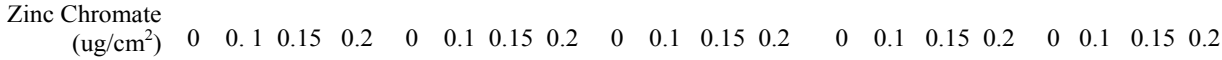

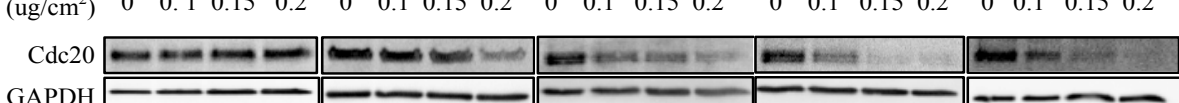

GAPDH

- -

Figure 2: Particulate Cr(VI) Decreases Cdc20 Protein Levels. This figure shows that zinc chromate decreases Cdc20 protein levels after $24-120 \mathrm{~h}$ exposure. Protein expression was measured with western blotting. GAPDH was used as a loading control. A) Protein expression level in total population of cells. B) Representative western blot image of Cdc20 expression in total population of cells. C) Protein expression level in mitotic population of cells collected with shake off. D) Representative western blot image of Cdc20 expression level in mitotic cells. Data represent an average of three independent experiments \pm the standard error of the mean. *Statistically different from control $(p<0.05)$. †Statistically different from control $(p<0.01)$. \#Statistically different from $24 \mathrm{~h}$ treatment at this concentration $(p<0.05)$.

both $24 \mathrm{~h}$ and $120 \mathrm{~h}$ (Figure $3 \mathrm{~A}$ ). Exposure to $0.2 \mathrm{ug} / \mathrm{cm}^{2}$ zinc chromate decreased levels of phosphorylated Cdc20 by $20 \%$ relative to control at both 24 and $120 \mathrm{~h}$.

We also considered the effect of zinc chromate on Mad2 protein levels. Mad2 is one of the proteins that interacts with $\mathrm{Cdc} 20$ at the kinetochore and sequesters it in the MCC complex preventing Cdc20 from activating APC/C (26-28). We found that zinc chromate also induced a concentration-dependent decrease in Mad2 protein levels beginning at $48 \mathrm{~h}$ (Figures $4 \mathrm{~A}$ and $4 \mathrm{~B}$ ). For example, a $96 \mathrm{~h}$ exposure to $0.1,0.15$ and $0.2 \mathrm{ug} / \mathrm{cm}^{2}$ zinc chromate decreased Mad2 levels to 30,50 and $70 \%$ relative to control, respectively. This effect was also 
A

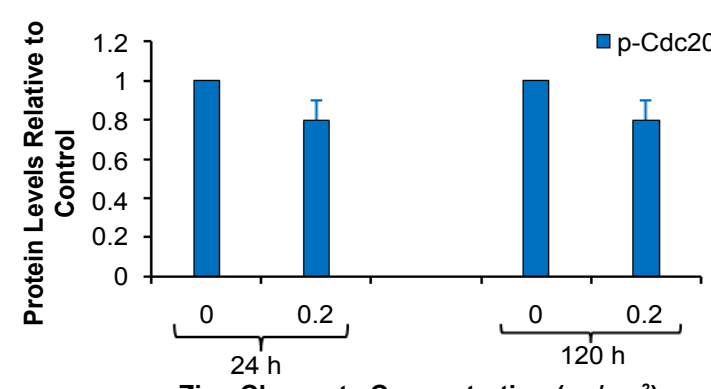

Zinc Chromate Concentration (ug/ $\mathrm{cm}^{2}$ )

B

\begin{tabular}{|c|c|c|c|c|c|}
\hline Time $(\mathrm{h})$ & & & 12 & & \\
\hline $\begin{array}{r}\text { Zinc Chromate } \\
\left(\mathrm{ug} / \mathrm{cm}^{2}\right)\end{array}$ & 0 & 0.2 & 0 & 0.2 & \\
\hline $\mathrm{pCdc} 20$ & - & 列 & 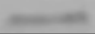 & +5 & IP:Cdc20 \\
\hline pCdc 20 & 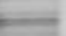 & +5 & sis & 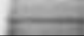 & Input \\
\hline
\end{tabular}

Figure 3: Particulate $\mathrm{Cr}(\mathrm{VI})$ Decreases Phosphorylated Cdc20 Protein Levels. This figure shows that zinc chromate decreases phosphorylated Cdc20 protein levels after 24-120 h exposure. Immunoprecipitation was carried out from whole cell lysates with anti-Cdc20 beads and western blotting was performed with anti-phosphoserine antibody. A) Phosphorylated Cdc20 levels after a 24 or $120 \mathrm{~h}$ exposure to $0.2 \mathrm{ug} / \mathrm{cm}^{2}$ zinc chromate. Data represent an average of two experiments \pm standard error of the mean. B) Representative western blot images of phosphorylated Cdc20 protein levels after total-Cdc20 immunoprecipitation.

still evident when we limited our analysis to only those cells in mitosis (Figures 4C and 4D).

\section{Chronic exposure to zinc chromate decreases interactions between phosphorylated $\mathrm{Cdc} 20$ and Mad2}

Given that both Cdc20 and Mad2 protein levels were decreased, we considered the interaction of the two proteins as Mad2 binds to phopsphorylated-Cdc20 and sequesters it in the MCC complex preventing Cdc20 from activating APC/C [26-29]. Since zinc chromate decreased Cdc20 localization, we determined whether it also decreased phosphoryated-Cdc20-Mad2 interactions. We found that chronic zinc chromate exposure reduced the interaction of phosphorylated-Cdc20 with Mad2 (Figures 5A and 5B). For example, exposure to $0.2 \mathrm{ug} / \mathrm{cm}^{2}$ zinc chromate decreased the ratio of Mad2/pCdc20 from $90 \%$ at $24 \mathrm{~h}$ to $40 \%$ at $120 \mathrm{~h}$ indicating less protein was binding together.

\section{Chronic Exposure to Zinc Chromate InducesSAC Bypass}

Our previous reports indicated that $\mathrm{Cr}(\mathrm{VI})$ was bypassing the SAC and not eliminating it. Specifically, we found the SAC to remain functional during $\mathrm{Cr}(\mathrm{VI})$ exposure as triggering the SAC by adding colchicine, reduced the amount of SAC bypass caused by zinc chromate $[7,8]$. In this study, we further investigated whether the SAC was functional by again triggering it with either demecolchicine or nocodazole. We found that triggering the checkpoint did reverse the effects of zinc chromate on Cdc20-kinetochore localization, but not on its effects on Cdc20 or Mad2 protein levels (Figures 6 A-E).

\section{Discussion}

Particulate $\mathrm{Cr}(\mathrm{VI})$ compounds are established human lung carcinogens, however, their underlying carcinogenic mechanisms are not well understood. The best explanation appears to be based on their ability to induce CIN including structural and numerical chromosomal changes $[7,8]$. Our previous studies show that chronic exposure to particulate $\mathrm{Cr}(\mathrm{VI})$ induces concentration- and time-dependent increases in CIN manifested as aneuploidy, centromere spreading, premature centromere division and premature anaphase $[7,8]$. Further, we found that bypassing the SAC was part of the mechanism for particulate $\mathrm{Cr}(\mathrm{VI})$-induced $\mathrm{CIN}[7,8]$. Here we extend those findings and begin defining how $\mathrm{Cr}(\mathrm{VI})$ bypasses the SAC on a cellular and molecular basis.

In mitosis, Cdc20 localizes to the kinetochore during checkpoint activation where it is bound and inhibited until the kinetochore is

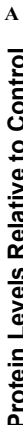

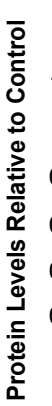

$\square \operatorname{Mad} 2$

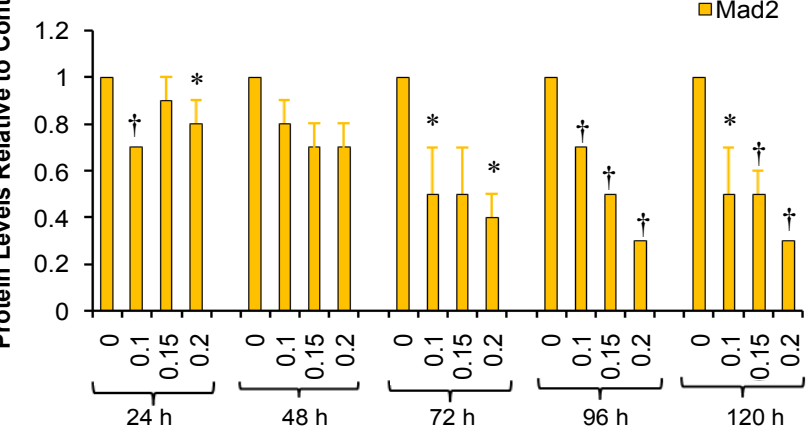

Zinc Chromate Concentration (ug/ $\left.\mathrm{cm}^{2}\right)$
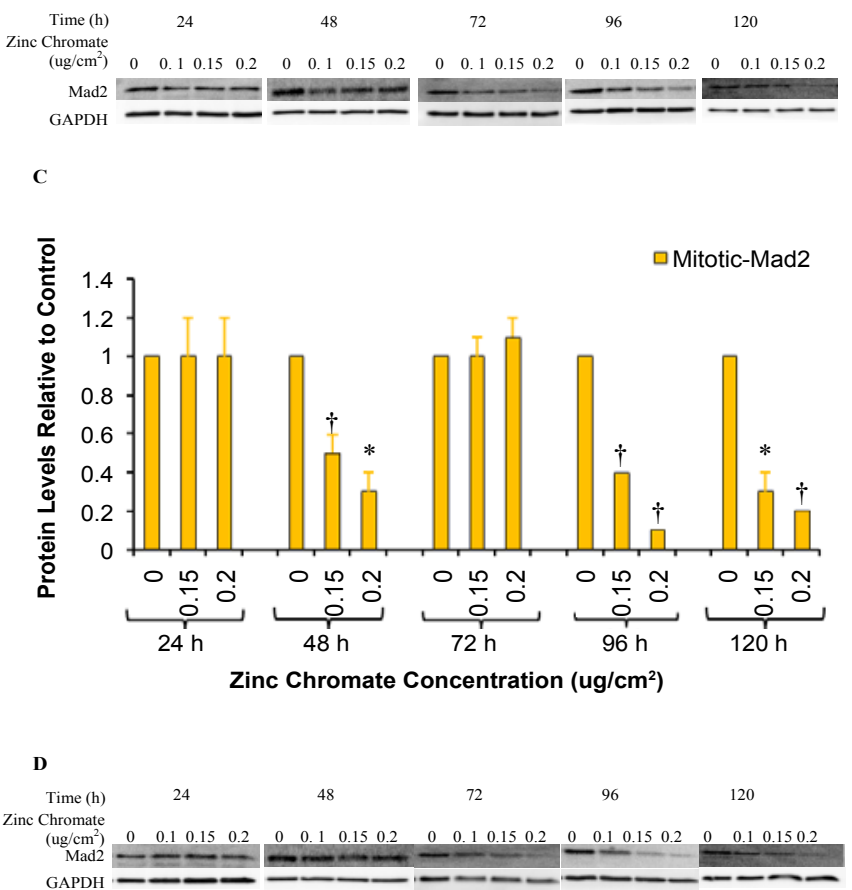

Figure 4: Particulate $\mathrm{Cr}(\mathrm{VI})$ Decreases Mad2 Protein Levels. This figure shows that zinc chromate decreased Mad2 protein levels after 24-120 h exposure. Protein expression was measured with western blotting. GAPDH was used as a loading control. A) Protein expression level in total population of cells. B) Representative western blot image of Mad2 expression in total population of cells. C) Protein expression level in mitotic population of cells. D) Representative western blot image of Mad2 expression in mitotic cells. Data represent an average of three independent experiments \pm the standard error of the mean. ${ }^{*}$ Statistically different from control $(p<0.05)$. $†$ Statistically different from control $(p<0.01)$. 


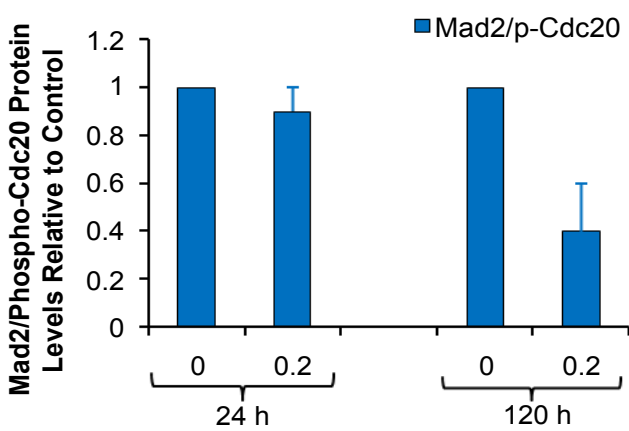

Zinc Chromate Concentration (ug/ $\mathrm{cm}^{2}$ )

B

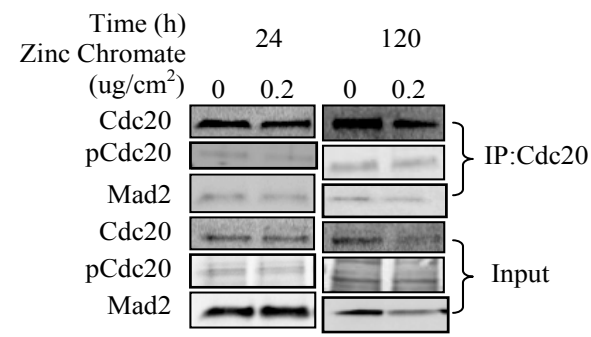

Figure 5: Particulate $\mathrm{Cr}(\mathrm{VI})$ Alters Mad2 and Cdc20 Protein Interactions. This figure shows that zinc chromate alters Mad2-Cdc20 interactions after 24 or $120 \mathrm{~h}$ exposure. Co-immunoprecipitation was carried out from whole cell lysates with anti-Cdc20 beads and western blotting was performed with indicated antibodies. A) Mad2-phosphorylated Cdc20 interactions are decreased after both 24 and $120 \mathrm{~h}$ exposure with a dramatic impact at 120 h. B) Representative image of total-Cdc20, phosphorylated Cdc20 and totalMad2 protein levels following Cdc20 immunoprecipitation after 24 and $120 \mathrm{~h}$ exposure. Data represent an average of two experiments \pm standard error of the mean

properly attached to microtubules. Disrupting Cdc20 localization to the kinetochores could attenuate the checkpoint. One study has shown that Cdc20 hypomorphic mice exhibit a decreased Cdc20 localization to the kinetochores which led to progressive aneuploidy and premature sister chromatid separation. Our data are the first report of a chemical carcinogen disrupting Cdc20 localization and the observations that particulate $\mathrm{Cr}(\mathrm{VI})$ disrupts this localization in a time and concentration-dependent manner are consistent with our previous reports of SAC bypass at these concentrations $[7,8]$.

In general, it is unknown how the lack of Cdc20 kinetochore localization leads to SAC bypass. When the SAC is activated, Cdc20 is sequestered by binding to Mad2 at kinetochores to inhibit the activity of the APC by forming an inactive complex with Cdc20 and APC. Thus, one possibility is that decreasing Cdc20 localization to the kinetochores could lead to decreased interactions of Cdc20 with Mad2 and/or other checkpoint proteins at the kinetochores, resulting in more Mad2-free Cdc20 to prematurely activate APC. Consistent with this possibility, we did find that zinc chromate decreased the interaction of Mad2 and phosphorylated Cdc20. These data are also consistent with observations that arsenic, another human carcinogen, decreased interactions of Mad2 with the APC/Cdc20 complex, although that study did not measure the direct interaction between Mad2 and Cdc20 [30].

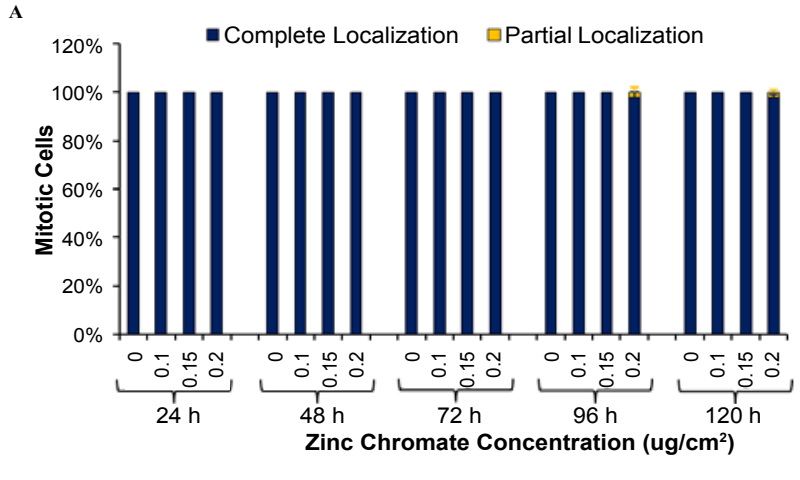

B
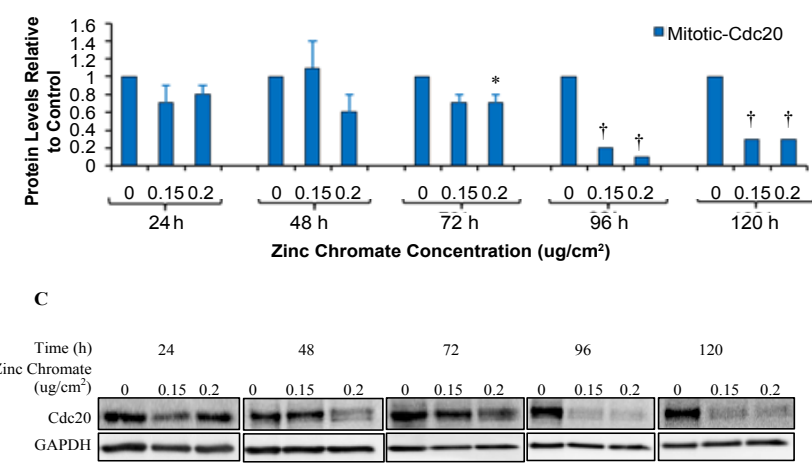

D

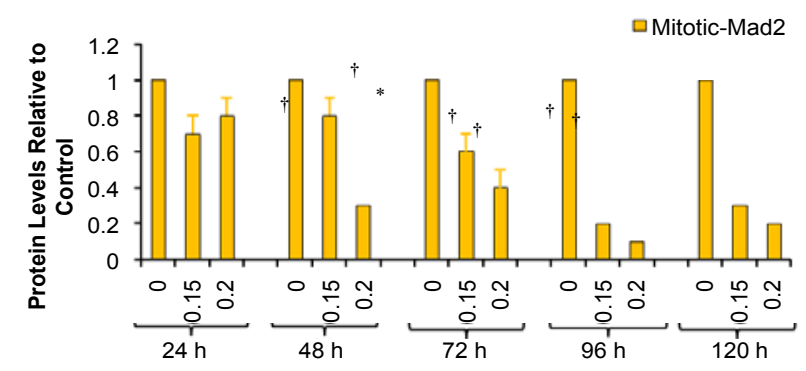

Zinc Chromate Concentration (ug/ $\mathrm{cm}^{2}$ )$$
\mathbf{E}
$$

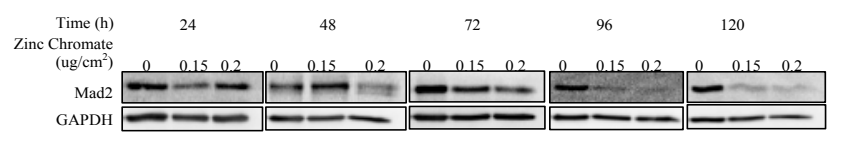

Figure 6: Particulate $\mathrm{Cr}(\mathrm{VI})$ Causes SAC Bypass not Elimination. This figure shows the effects of triggering the SAC on zinc chromate effects on Cdc20 kinetochore localization and expression levels, and Mad2 protein expression levels. A) One hour before the end of zinc chromate treatment, cells were treated with $0.1 \mathrm{ug} / \mathrm{ml}$ demecolchicine. Demecolchicine reversed zinc chromate effects on localization. Cells were fixed after the treatment, followed by immunostaining using anti-Cdc20 and centromere antibodies. B) Sixteen hours before the end of zinc chromate treatment, cells were treated with $0.4 \mathrm{ug} /$ $\mathrm{ml}$ nocodazole. Nocodazole had no effect on zinc chromate-induced decreases in Cdc20 protein levels in mitotic cells. C) Representative western blot image of Cdc20 expression in nocodazole co-treated cells. D) Nocodazole had no effect on zinc chromate-induced decreases in Mad2 protein levels in mitotic cells. E) Representative western blot image of Mad2 expression in nocodazole co-treated cells. Protein expression was measured with western blot using anti-Cdc20 and Mad2 antibodies. GAPDH was used as a loading control. Data represent an average of three independent experiments \pm the standard error of the mean. *Statistically different from control $(p<0.05)$. $†$ Statistically different from control $(p<0.01)$. 
Citation: Karri ND, Xie H, Wise JP (2013) Chronic Exposure to Particulate Hexavalent Chromium Alters Cdc20 Protein Localization, Interactions and Expression. J Carcinogene Mutagene 4: 140. doi:10.4172/2157-2518.1000140

Page 7 of 8

The role of phosphorylated Cdc20 is also not well understood. It has been reported that phosphorylated Cdc20 binds to Mad2 to regulate the spindle checkpoint function [26,31]. Consistent with that finding, we find that zinc chromate decreases the interactions of phosphorylated Cdc20 with Mad2, potentially freeing phosphorylated Cdc20 to activate APC. How $\mathrm{Cr}(\mathrm{VI})$ interferes with the Cdc20/Mad2 interactions in unknown. There is a metal binding motif on Cdc20 that is near the Mad2-binding domain [32]. Thus, one possibility, albeit untested, is that $\mathrm{Cr}$ binds to that metal binding motif and interferes with Mad2 binding.

Zinc chromate decreased Mad2 levels. These data are consistent with our previous study showing that lead chromate decreased Mad2 protein levels and suggest this outcome may be a common mechanism for particulate chromates. It is also consistent with other studies showing that arsenic induces SAC bypass and decreases Mad2 expression levels [33] and that 2,3,7,8-tetrachlorodibenzo-p-dioxin (TCDD)- suppresses the expression of Mad2 resulting in increasing CIN [34]. Altogether, these data suggest that Mad2 disruption may be a common mechanism for chemical carcinogens to induce CIN.

We continue to find that particulate $\mathrm{Cr}(\mathrm{VI})$ is bypassing the SAC rather than damaging or eliminating it. Previously, we reported that triggering the checkpoint with spindle poisons in particulate $\mathrm{Cr}(\mathrm{VI})$-treated cells decreases the observed effects indicating the SAC was functional and being bypassed $[7,8]$. This study supports that conclusion as our data show that triggering the checkpoint with spindle poisons in zinc chromate-treated cells reverses the disruption of Cdc20 kinetochore localization. The decrease in Cdc20 protein levels we found may also indicate that the checkpoint is functional and being bypassed. A previous study shows that spindle poisons prevent the SAC from being satisfied and arrest the cells in metaphase and while doing so decrease Cdc20 protein levels [34]. This outcome suggests that decreased Cdc20 levels may be a specific response to mitotic spindle checkpoint activation [34]. This possibility is also consistent with another previous report that cadmium decreases Cdc20 protein levels leading to prometaphase arrest [35].

Thus, we hypothesize that the mechanism for particulate chromateinduced carcinogenesis starts with $\mathrm{Cr}(\mathrm{VI})$ particles impacting at bronchial bifurcation sites in the lung and dissolving outside the cell. Once inside the cell, $\mathrm{Cr}(\mathrm{VI})$ is reduced to $\mathrm{Cr}(\mathrm{III})$, which accumulates in the cell with time. Some cells function normally in mitosis, but in a subset of cells $\mathrm{Cr}$ (III) binds to Cdc20 and disrupts Mad2-mediated Cdc20 localization to the kinetochore and the repressive function of the mitotic checkpoint complex. This outcome allows these cells to bypass the checkpoint and enter anaphase without proper microtubulekinetochore attachment resulting in centromere spreading, premature centromere division, premature anaphase and ultimately aneuploidy. Further work is aimed at determining the mechanistic links between $\mathrm{Cr}$ (III) binding and the effects on Cdc20 and the impact on other SAC proteins.

\section{Acknowledgments}

We thank Geron Corporation for the use of the hTERT materials, Dr. William Earnshaw at the Wellcome Trust Centre for Cell Biology, Edinburgh for the use of anti-centromere serum antibody. We also like to thank Christy Gianios, Jr. and Shou-ping Huang for technology and administrative support. This work is supported by NIEHS grant ES016893 (J.P.W.) and the Maine Center for Toxicology and Environmental Health. The content is solely the responsibility of the authors and does not necessarily represent the official views of the National Institute of Environmental Health Sciences or the National Institutes of Health.

\section{References}

1. IARC (1990) The evaluation of carcinogenic risks to humans: chromium, nicke and welding. International Agency for Cancer Research, Lyons, France, vol 49.

2. Léonard A, Lauwerys RR (1980) Carcinogenicity and mutagenicity of chromium Mutat Res 76: 227-239.

3. Levy LS, Venitt S (1986) Carcinogenicity and mutagenicity of chromium compounds: the association between bronchial metaplasia and neoplasia. Carcinogenesis 7: 831-835.

4. Patierno SR, Banh D, Landolph JR (1988) Transformation of C3H/10T1/2 mouse embryo cells to focus formation and anchorage independence by insoluble lead chromate but not soluble calcium chromate: relationship to mutagenesis and internalization of lead chromate particles. Cancer Res 48 : 5280-5288.

5. Haruki N, Harano T, Masuda A, Kiyono T, Takahashi T, et al. (2001) Persisten increase in chromosome instability in lung cancer: possible indirect involvement of p53 inactivation. Am J Pathol 159: 1345-1352.

6. Rodrigues CF, Urbano AM, Matoso E, Carreira I, Almeida A, et al. (2009) Human bronchial epithelial cells malignantly transformed by hexavalent chromium exhibit an aneuploid phenotype but no microsatellite instability Mutat Res 670: 42-52.

7. Wise SS, Holmes AL, Xie H, Thompson WD, Wise JP Sr (2006) Chronic exposure to particulate chromate induces spindle assembly checkpoint bypass in human lung cells. Chem Res Toxicol 19: 1492-1498.

8. Holmes AL, Wise SS, Pelsue SC, Aboueissa AM, Lingle W, et al. (2010) Chronic exposure to zinc chromate induces centrosome amplification and spindle assembly checkpoint bypass in human lung fibroblasts. Chem Res Toxicol 23: 386-395

9. Musacchio A, Salmon ED (2007) The spindle-assembly checkpoint in space and time. Nat Rev Mol Cell Biol 8: 379-393.

10. Sudakin V, Chan GK, Yen TJ (2001) Checkpoint inhibition of the APC/C in HeLa cells is mediated by a complex of BUBR1, BUB3, CDC20, and MAD2. Cell Biol 154: 925-936

11. Schott EJ, Hoyt MA (1998) Dominant alleles of Saccharomyces cerevisiae CDC20 reveal its role in promoting anaphase. Genetics 148: 599-610.

12. Yuan B, Xu Y, Woo JH, Wang $Y$, Bae YK, et al. (2006) Increased expression of mitotic checkpoint genes in breast cancer cells with chromosomal instability. Clin Cancer Res 12: 405-410.

13. Li M, Fang X, Wei Z, York JP, Zhang P (2009) Loss of spindle assembly checkpoint-mediated inhibition of Cdc20 promotes tumorigenesis in mice. J Cell Biol 185: 983-994.

14. Díaz-Rodríguez E, Álvarez-Fernández S, Chen X, Paiva B, López-Pérez R, et al. (2011) Deficient spindle assembly checkpoint in multiple myeloma. PLoS One 6: e27583.

15. Jin F, Hamada M, Malureanu L, Jeganathan KB, Zhou W, et al. (2010) Cdc20 is critical for meiosis I and fertility of female mice. PLoS Genet 6.

16. Yen $\mathrm{AH}$, Yang JL (2010) Cdc20 proteolysis requires p38 MAPK signaling and Cdh1-independent APC/C ubiquitination during spindle assembly checkpoin activation by cadmium. J Cell Physiol 223: 327-334.

17. Wise SS, Elmore LW, Holt SE, Little JE, Antonucci PG, et al. (2004) Telomerase-mediated lifespan extension of human bronchial cells does not affect hexavalent chromium-induced cytotoxicity or genotoxicity. Mol Cell Biochem 255: 103-111

18. Xie H, Holmes AL, Young JL, Qin Q, Joyce K, et al. (2009) Zinc chromate induces chromosome instability and DNA double strand breaks in human lung cells. Toxicol Appl Pharmacol 234: 293-299.

19. Howell BJ, Moree B, Farrar EM, Stewart S, Fang G, et al. (2004) Spindle checkpoint protein dynamics at kinetochores in living cells. Curr Biol 14: 953 964.

20. Kallio MJ, Beardmore VA, Weinstein J, Gorbsky GJ (2002) Rapid microtubuleindependent dynamics of $\mathrm{Cdc} 20$ at kinetochores and centrosomes in mammalian cells. J Cell Biol 158: 841-847.

21. Li D, Morley G, Whitaker M, Huang JY (2010) Recruitment of Cdc20 to the kinetochore requires BubR1 but not Mad2 in Drosophila melanogaster. Mol Cell Biol 30: 3384-3395. 
Citation: Karri ND, Xie H, Wise JP (2013) Chronic Exposure to Particulate Hexavalent Chromium Alters Cdc20 Protein Localization, Interactions and Expression. J Carcinogene Mutagene 4: 140. doi:10.4172/2157-2518.1000140

Page 8 of 8

22. Li M, York JP, Zhang P (2007) Loss of Cdc20 causes a securin-dependent metaphase arrest in two-cell mouse embryos. Mol Cell Biol 27: 3481-3488.

23. Malureanu L, Jeganathan KB, Jin F, Baker DJ, van Ree JH, et al. (2010) Cdc20 hypomorphic mice fail to counteract de novo synthesis of cyclin B1 in mitosis. J Cell Biol 191: 313-329.

24. Mondal G, Sengupta S, Panda CK, Gollin SM, Saunders WS, et al. (2007) Overexpression of Cdc20 leads to impairment of the spindle assembly checkpoint and aneuploidization in oral cancer. Carcinogenesis 28: 81-92.

25. Nilsson $\mathrm{J}$ (2011) Cdc20 control of cell fate during prolonged mitotic arrest: do Cdc20 protein levels affect cell fate in response to antimitotic compounds? Bioessays 33: 903-909.

26. Chung E, Chen $\mathrm{RH}$ (2003) Phosphorylation of Cdc20 is required for its inhibition by the spindle checkpoint. Nat Cell Biol 5: 748-753.

27. Fang G, Yu H, Kirschner MW (1998) The checkpoint protein MAD2 and the mitotic regulator CDC20 form a ternary complex with the anaphase-promoting complex to control anaphase initiation. Genes Dev 12: 1871-1883.

28. Fang G (2002) Checkpoint protein BubR1 acts synergistically with Mad2 to inhibit anaphase-promoting complex. Mol Biol Cell 13: 755-766.

29. Yudkovsky Y, Shteinberg M, Listovsky T, Brandeis M, Hershko A (2000)
Phosphorylation of Cdc20/fizzy negatively regulates the mammalian cyclosome/ APC in the mitotic checkpoint. Biochem Biophys Res Commun 271: 299-304.

30. Yih LH, Lee TC (2003) Induction of C-anaphase and diplochromosome through dysregulation of spindle assembly checkpoint by sodium arsenite in human fibroblasts. Cancer Res 63: 6680-6688.

31. D'Angiolella V, Mari C, Nocera D, Rametti L, Grieco D (2003) The spindle checkpoint requires cyclin-dependent kinase activity. Genes Dev 17: 25202525

32. Mondal G, Baral RN, Roychoudhury S (2006) A new Mad2-interacting domain of Cdc20 is critical for the function of Mad2-Cdc20 complex in the spindle assembly checkpoint. Biochem J 396: 243-253.

33. Oikawa K, Ohbayashi T, Mimura J, Iwata R, Kameta A, et al. (2001) Dioxin suppresses the checkpoint protein, MAD2, by an aryl hydrocarbon receptorindependent pathway. Cancer Res 61: 5707-5709.

34. Ge S, Skaar JR, Pagano M (2009) APC/C- and Mad2-mediated degradation of Cdc20 during spindle checkpoint activation. Cell Cycle 8: 167-171.

35. Yen AH, Yang JL (2010) Cdc20 proteolysis requires p38 MAPK signaling and Cdh1-independent APC/C ubiquitination during spindle assembly checkpoint activation by cadmium. J Cell Physiol 223: 327-334. 